\title{
REPRESENTACIONES DE GÉNERO EN LA PUBLICIDAD RADIOFÓNICA. UN ANÁLISIS COMPARATIVO
}

\section{GENDER REPRESENTATIONS IN RADIO ADVERTISEMENTS.}

\section{A COMPARATIVE ANALYSIS}

\section{AUTOR}

Teresa Piñeiro-Otero: Profesora de la Facultade de Ciencias de la Comunicación, Universidade da Coruña, A Coruña.

teresa.pineiro@udc.es

\section{RESUMEN}

El papel que asumen la publicidad y los medios de comunicación en el proceso de formación del individuo ha suscitado la preocupación social por el tipo de representaciones que éstos vehiculan. Una circunstancia que se hace especialmente patente en el ámbito de las representaciones de género.

Este particular tratamiento que la publicidad da a las representaciones femeninas y masculinas ha constituido el objeto de estudio de numerosas investigaciones en las últimas décadas. Investigaciones que han sido abordadas, fundamentalmente, desde la perspectiva de la publicidad televisiva, dejando relegado al medio sonoro.

El presente trabajo ha tenido por objeto analizar el tratamiento que la publicidad radiofónica española da a las representaciones de género, con la intención de comparar dichos resultados con aquellos aportados por estudios precedentes sobre la estereotipia sonora en otros ámbitos (Reino Unido y Portugal).

\section{PALABRAS CLAVE}

Publicidad - Radio - Estereotipos de género 


\section{ABSTRACT}

Advertising and media paper in socialization process has caused social worry because of representations in their messages. This circumstance becomes especially patent in the case of gender representations.

The particular treatment that advertisements give to feminine and masculine representations has constituted several research aim in last decades. Some research focuses, fundamentally, in television advertisement.

Present study aim has been to analyze gender representations on Spanish radio advertisement to compare this results with another sound stereotypes research in other fields (United Kingdom and Portugal).

\section{KEY WORDS}

Advertising- Radio - Gender stereotypes

\section{ÍNDICE}

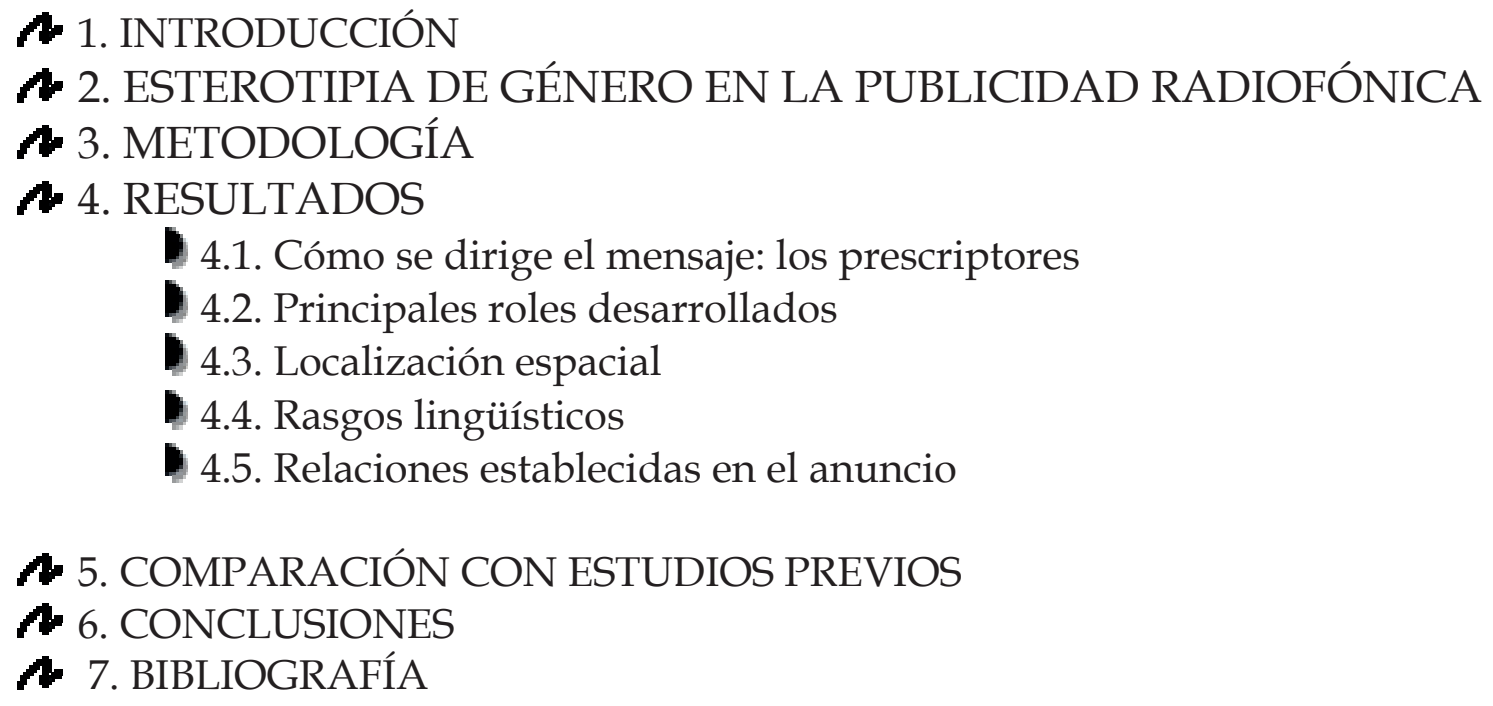

\section{INTRODUCCIÓN}

El papel asumido por los medios de comunicación y la publicidad en el proceso de socialización del individuo ha suscitado la preocupación de diversos actores sociales por el 
tipo de imágenes que vehiculan sus mensajes. Una preocupación que adquiere particular relevancia en lo que se refiere a la estereotipia de género $\mathrm{y}$, más concretamente, al tratamiento que reciben los personajes femeninos y a su invisibilización en determinados papeles.

La implicación de los medios de comunicación y la publicidad en la construcción de los imaginarios sociales ha sido frecuentemente tratada por los estudios de género y comunicación. Unas investigaciones cuyo inicio se encuadra en la década de los 70 como parte de los denominados Gender Studies.

Autores como Durkin (1985) han considerado la relevancia que un seguimiento regular de los mensajes mediáticos puede presentar para el análisis longitudinal de la relación establecida entre medios de comunicación y sociedad. Un análisis que, siguiendo a Furham y Schofield (1986), adquiere una especial proyección en el ámbito de los "primary mass media" debido a su relevante grado de penetración.

De este modo, la utilización que los mensajes publicitarios realizan de las representaciones de género así como el abuso de las representaciones femeninas, como sujetos u objetos, ha constituido el centro de atención de numerosas investigaciones en las últimas décadas. Un corpus teórico en el que destacan, entre otros, los trabajos de Courtney y Lockeretz (1971); Courtney y Whipple (1974); McArthur y Resko (1975); Goffman (1976); Manstead y McCulloch (1981); Durkin (1985); Furnham y Schofield (1986); Harris y Stobart (1986); Rak y McCullen (1987); Gilly (1988); Furham y Voli (1989); Lovdal (1989); Craig (1992); Furnham y Bitar (1993); Kolbe y Langefeld (1993); Hurtz y Durkin (1997); Neto y Pinto (1998); Furnham y Thomson (1999); Furnham y Mak (1999); Neto y Santos (2004)1.

\footnotetext{
${ }^{1}$ La selección de dichos trabajos se ha llevado a cabo a partir del número de referencias en estudios posteriores; criterio que ha provocado la ausencia de investigaciones en los últimos años. Asimismo, dado el objeto de interés de dicha investigación, se ha potenciado la selección de trabajos relativos al medio radiofónico promoviendo -de este modo- su sobrerrepresentación en los estudios considerados de referencia.
} 
En el contexto español, la investigación en torno al tratamiento publicitario de las representaciones de género/femeninas dio comienzo durante los años 80, aunque ha sido en la última década cuando ha alcanzado mayo proyección. Dentro de este ámbito resultan destacables los trabajos de Méndiz (1988); Peña-Marín y Fabretti (1990); Bermejo, Carballido, Patricio y Ramos (1994); del Moral (2000); Bernárdez (2000); González Solaz y García Cubells (2001); Sánchez Aranda, García Ortega, Grandío y Berganza Conde, (2002), entre otros.

Ambos corpus teóricos, nacional e internacional, presentan una mayoría de investigaciones que han focalizado su objeto de estudio en la publicidad televisiva. Un enfoque que llevaría a pensar en la televisión como el medio de comunicación cuyos mensajes presentan unos estereotipos de género más plausibles. Sin embargo, la realidad es que el medio televisión adolece de un exceso de visibilización que lo sitúa en el punto de mira de asociaciones y entidades reguladoras; no en vano, todavía constituye el medio más consumido por el público (Estudio General de Medios, 2011).

\section{ESTEROTIPIA DE GÉNERO EN LA PUBLICIDAD RADIOFÓNICA}

En el caso del medio radiofónico, la revisión de literatura científica sobre la estereotipia de género/femenina en la publicidad ha puesto de relevancia la escasa presencia de investigaciones que han seleccionado el medio sonoro como objeto de estudio. Concretamente se trata de los trabajos de Furham y Schofield (1986), Hurtz y Durkin (1997), Furham y Thomson (1999), Neto y Santos (2004) o Monk-Turner y otros (2007) en el ámbito internacional, y los de Gil (2007), Piñeiro-Otero (2009), Barbeito y otros (2010) en España. 
Esta menor presencia de estudios centrados en el medio radiofónico podría vincularse a la existencia, en la publicidad sonora, de un grupo de estereotipos de género más igualitarios y coherentes con la realidad; una circunstancia que parece confirmar el escaso volumen de denuncias por publicidad sexista efectuadas ante el Observatorio de la Imagen de las Mujeres².

Sin embargo, los trabajos realizados en torno al medio radiofónico han podido constatar que -al igual que sucede con la televisión- la radio construye sus mensajes a partir de una serie de imágenes de género con un alto grado de estereotipia, especialmente en lo que respecta a las femeninas (Furham y Schofield, 1986; Furham y Thomson, 1999; Neto y Santos, 2004 o Gil, 2007).

La percepción de un tratamiento más respetuoso de las representaciones de ambos sexos en la publicidad sonora se fundamenta en el hecho de que, debido a la carencia de imagen física de la radio, el proceso de estereotipia se configura de un modo diferente al de los restantes media.

En su estudio "Sex role stereotyping in British radio advertisements" (1986), pionero en la investigación en torno a la estereotipia de género en el medio sonoro, Furham y Schofield concluyeron que en la radio los personajes masculinos con frecuencia aparecían representados como autoridades, narradores o celebridades, mientras que las mujeres solían representarse como usuarias de productos en escenarios mayoritariamente domésticos. Una conclusión que puede ser aplicada, con apenas variaciones, a la publicidad radiofónica actual (Neto y Santos, 2004; Gil, 2007; Monk-Turner y otros, 2007; (Barbeito y otros, 2010).

\footnotetext{
${ }^{2}$ Según el último informe del Observatorio de la Imagen de las Mujeres del Instituto de la Mujer (antes conocido como Observatorio de la Publicidad) el porcentaje de denuncias efectuadas contra la publicidad en la radio fue de un $5,6 \%$, frente al 42\% de la televisión, el 15,4\% de Internet o el 12\% de prensa (Instituto de la Mujer, 2009).
} 
Estudios como los de Furham y Thomson (1999) o de Neto y Santos (2004) continúan mostrando una infrarrepresentación de los personajes femeninos en la publicidad radiofónica (en torno al 21\%), así como su ausencia en aquellos papeles más relevantes dentro del mensaje publicitario, como el personaje principal, autoridad o narrador.

En efecto, la representación que los mensajes publicitarios vehiculan de los personajes femeninos muestra una trayectoria diametralmente opuesta a la de los masculinos, en función de variables como tipología de rol desempeñado, localización espacial, relación desarrollada en la interacción publicitaria, etc.

El objeto del presente trabajo ha sido el de analizar el tratamiento que la publicidad radiofónica española da a las representaciones de género en sus mensajes, especialmente en lo que respecta a las femeninas, en busca de establecer comparación con aquellos resultados aportados por estudios precedentes sobre la estereotipia publicitaria sonora en otros ámbitos (Reino Unido y Portugal).

\section{METODOLOGIA}

Con la intención de conocer el tipo de representaciones de género vehiculadas por la publicidad radiofónica española, se estableció el análisis de contenido como metodología de investigación. Análisis que se llevó a cabo sobre una selección de publicidad muy concreta: aquellas piezas presentadas al Festival Publicitario de San Sebastián desde la creación del galardón de radio (1996) hasta su última edición antes de su apertura al mundo latino (2002).

De este modo, el universo de estudio del presente trabajo estuvo configurado por un total de 915 piezas presentadas a la categoría de radio del Festival Publicitario de San Sebastián entre los años 1996 y 2002 (de la edición XI del certamen hasta la XVII, ambas inclusive), de las que se seleccionaron aquellas en las que apareciese, al menos, una voz femenina. Un 
total de 379 anuncios (que suponen un 41\% de la selección inicial) que delata una infrarrepresentación de los personajes femeninos en la publicidad radiofónica, frente a los masculinos.

\section{Gráfico 1. Porcentaje de anuncios radiofónicos con personajes femenino.}

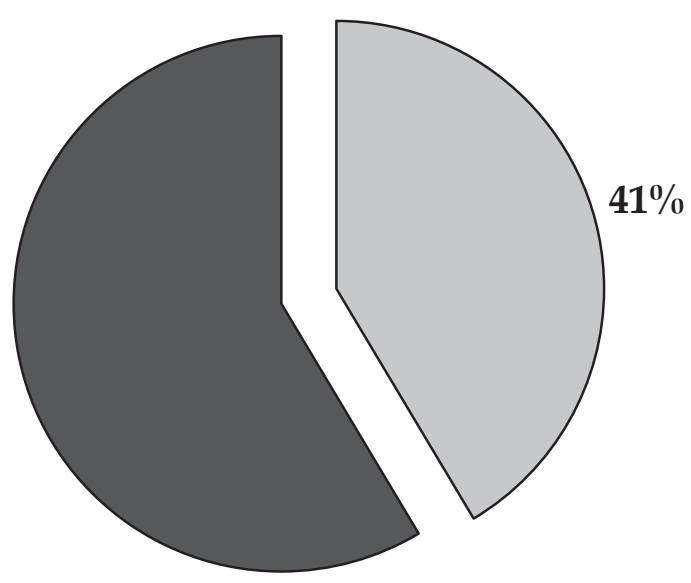

Fuente. Elaboración propia.

Esta selección permitió circunscribir la muestra de estudio al ámbito español y acotarla a un determinado tipo de publicidad, de mayor calidad que el promedio de los anuncios radiofónicos. Calidad que en este caso se refiere a la correcta adecuación del mensaje publicitario al medio sonoro, así como a sus posibilidades expresivas a través del empleo creativo de los diferentes componentes del lenguaje radiofónico.

Para llevar a cabo el estudio de las representaciones femeninas y masculinas presentes en la publicidad radiofónica de la muestra se diseñó una herramienta de trabajo con la que poder analizar y clasificar las diferentes cuñas seleccionadas, así como los personajes unidades de análisis. Unos personajes que, siguiendo los estudios precedentes en el ámbito del medio sonoro (Furham y Schofield, 1986; Furham y Thomson, 1999; Neto y Santos, 2004), van a limitarse a los dos protagonistas principales de cada anuncio; un total 
de 652 individuos considerados unidad de análisis en los que destaca una mayoría femenina.

Gráfico 2. Personajes unidad de análisis en función del género.

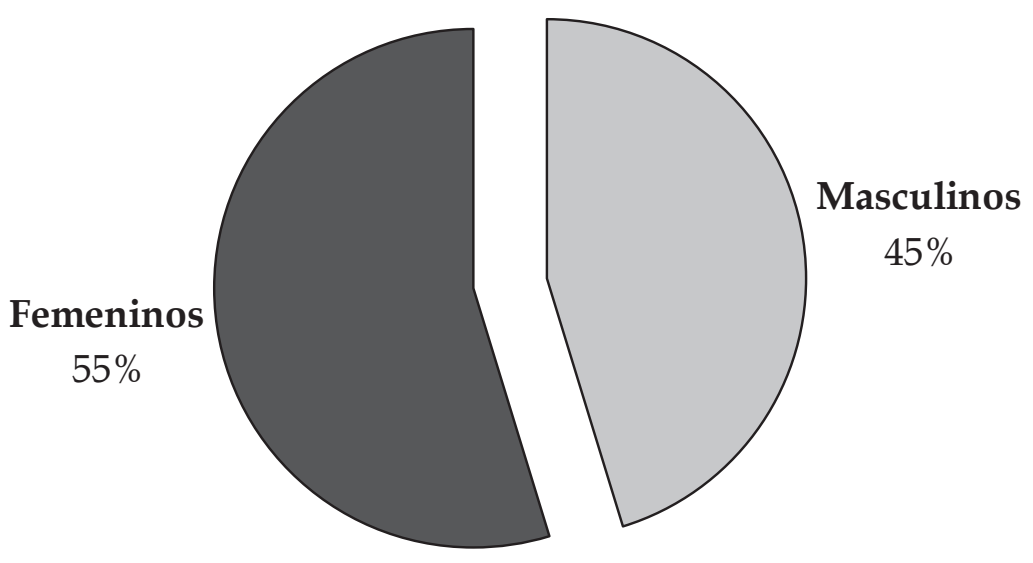

Fuente. Elaboración propia.

En la elaboración de una herramienta de análisis adecuada al objeto de análisis se tomó como referencia, al igual que tantos trabajos precedentes, el clásico estudio de McArthur y Resko: "The portrayal of men and women in American televisión commercials" (1975). Un estudio que se sustentó en siete variables diferentes: principales personajes, en qué se basa su credibilidad, rol desarrollado, localización, argumentación y recompensa.

Una ficha de trabajo que, pese a constituir el elemento estructurante de dicha investigación, ha sido precisa su revisión y adaptación al ámbito concreto de la publicidad radiofónica. En este proceso, a la herramienta final de estudio, se han incorporado nuevas categorías y subcategorías de análisis adoptadas de los trabajos de Gilly (1988), Furham y Thomson (1999) o Royo y otros (2005). 
Un total de trece ítems ordenados en tres bloques principales en función del foco de atención del análisis en cada momento: relacionadas con el mensaje (formato creativo, argumentos aportados, voz over); relacionadas con los personajes (género de los dos protagonistas, credibilidad, rol desarrollado, localización, registro lingüístico, acento, consideración social de los roles, relación entre ambos), relacionado con el producto (tipo de producto y recompensa).

Dado que el objeto de este artículo comprende la comparación de las representaciones femeninas y masculinas en la publicidad radiofónica española con los resultados aportados por trabajos precedentes en el ámbito de la estereotipia sonora de género, dicho estudio se ha centrado en aquellas variables vinculadas al personaje (género de los dos protagonistas, credibilidad, rol desarrollado, localización, registro lingüístico, acento, consideración social de los roles, relación entre ambos).

\section{RESULTADOS}

El estudio desarrollado sobre la publicidad radiofónica española ha permitido profundizar en el tipo de representaciones femeninas y masculinas que vehiculan sus mensajes. Unas representaciones de género que se construyen de modo diferente atendiendo a las variables analizadas.

\subsection{Cómo se dirige el mensaje: los prescriptores}

En la publicidad radiofónica tradicional resulta frecuente la presencia de un experto o autoridad, que se presenta como tal, cuya función es la de recomendar el productoservicio. Una tipología de prescriptor cuya credibilidad reside en su identidad (en el caso de que se trate de un personaje conocido), titulación o trabajo desempeñado. 
En el caso concreto de la muestra de estudio, solo uno de cada cuatro personajes presentes en la ficción publicitaria desarrollan identidades relacionadas con la prescripción de productos y servicios, sean de la credibilidad que sean: autoridad ( $0,6 \%$ de los personajes), prescriptores propiamente dichos ( $4 \%$ de los personajes) y/o usuarios satisfechos (en torno al 20\%). En efecto, las recomendaciones más frecuentes en lo que se refiere al producto-servicio publicitado vienen de parte de "clientes satisfechos" (que suponen el $80 \%$ de los prescriptores de la muestra).

Gráfico 3. Tipología de prescriptores en la muestra de estudio.

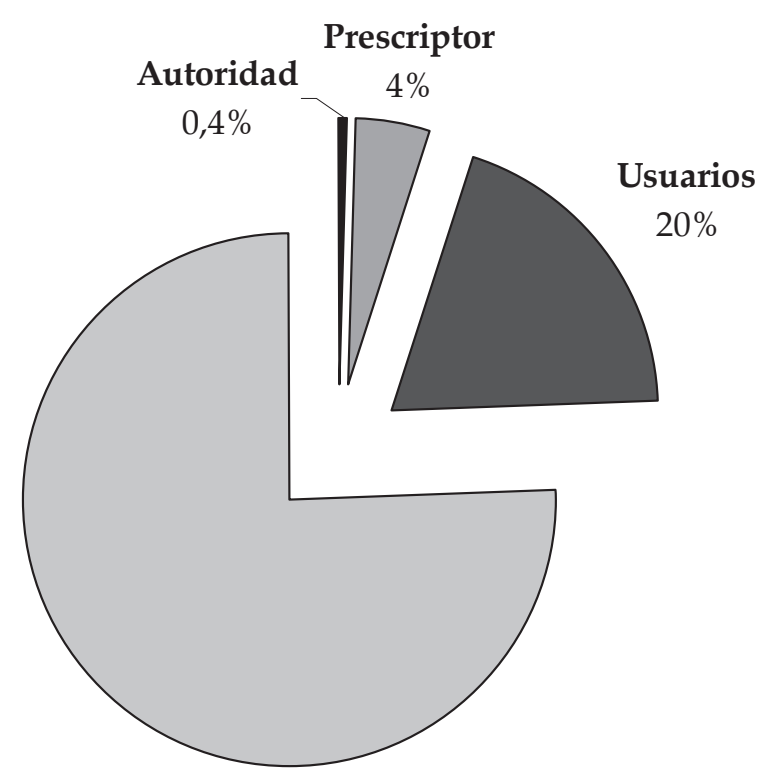

Fuente. Elaboración propia.

Si se atiende a los diversos tipos de prescriptores (autoridad, prescriptores propiamente dichos y usuarios) en función del género encontramos diferencias desde la perspectiva del lugar ocupado por los protagonistas masculinos y femeninos dentro de la interacción publicitaria. Un lugar que va a ser identificado con P1 y P2, en función de si se trata del personaje que inicia la interacción (P1) o con el que se relaciona (P2). 
En lo que respecta a los prescriptores publicitarios propiamente dichos (aquellos personajes que recomiendan el producto/servicio sin contar con una credibilidad de experto-autoridad o de cliente satisfecho), grupo al que pertenecen el $4 \%$ de los personajes analizados, se pueden señalar diferencias relevantes en cuanto al género. En efecto, existe un mayor número de prescriptores masculinos que dan inicio a la interacción publicitaria (que suponen alrededor del 67\% de los protagonistas varones en este papel); situación que se invierte en el caso de los prescriptores femeninos, con una mayor representación en el P2 (el 77\% de los prescriptores de género femenino).

El grupo más numeroso, los protagonistas de la muestra de estudio que se refieren al producto/servicio desde la posición de usuarios, también presentan diferencias atendiendo al lugar que ocupan los personajes femeninos y masculinos en la interacción publicitaria. Diferencias que, en este caso, resultan menos patente que en el de los prescriptores. Así se puede señalar una mayoría de protagonistas femeninas en el P1 (55\% de mujeres frente a 39\% de varones y el 6\% de personajes corales masculinos y femeninos), mientras que en el P2 este predominio se corresponde con los personajes masculinos (54\% de varones respecto al $42 \%$ de mujeres y el $4 \%$ de personajes corales).

\subsection{Principales roles desarrollados}

En lo que respecta a los roles asumidos por los personajes femeninos y masculinos de la muestra durante la interacción publicitaria, de gran relevancia en la caracterización de las representaciones radiofónicas, se puede destacar desde un primer momento tres roles de carácter sexista si se atiende a su vinculación exclusiva con personajes de un determinado género: ama de casa, teleoperadora (femeninos) y usuario $^{3}$ (masculino).

\footnotetext{
${ }^{3}$ El rol de "usuario" resulta diferente de aquel prescriptor que cuenta con “credibilidad de usuario". En el primer caso se hace referencia aquellos personajes cuya caracterización remite únicamente a un personaje que compra o hace uso de un determinado producto-servicio. En el segundo (prescriptor con credibilidad de usuario) se trata de un personaje que recomienda dicho producto-servicio a partir de una experiencia positiva de uso (que puede tener lugar en la
} 
Tabla 1. Roles desempeñados por los personajes objeto de estudio en función del género.

\begin{tabular}{|l|c|c|}
\hline & PERSONAJES FEMENINOS & PERSONAJES MASCULINOS \\
\hline ESPOSO/A & 34 & 33 \\
\hline PADRE/MADRE & 36 & 12 \\
\hline AMA DE CASA & 9 & 0 \\
\hline TRABAJADOR/A & 46 & 26 \\
\hline PERIODISTA & 18 & 17 \\
\hline TELEOPERADORA & 21 & 0 \\
\hline CELEBRIDAD & 9 & 7 \\
\hline NARRADOR & 18 & 24 \\
\hline NOVIO/A & 26 & 15 \\
\hline HIJO/A & 6 & 23 \\
\hline VECINO/A & 11 & 2 \\
\hline COMPAÑERO/A & 28 & 18 \\
\hline USUARIO & 0 & 11 \\
\hline NORELEVANTE & 15 & 21 \\
\hline PAPEL & 23 & 10 \\
\hline OTRO & 57 & 76 \\
\hline
\end{tabular}

Fuente. Elaboración propia.

Un análisis más pormenorizado señala el predominio de personajes femeninos en aquellos papeles que tradicionalmente le asignó la publicidad como el de ama de casa, madre, esposa (aunque solo aventaja en un personaje a los protagonistas masculinos), vecina, novia o teleoperadora; al tiempo que vincula los personajes masculinos a determinados roles como el de narrador.

En otros casos, la diferencia de los personajes en función del género está determinada por la selección concreta de la muestra, que llevó a polarizar determinados roles como el de trabajador, periodista o celebridad de la vida real, ente otros.

En definitiva, se puede subrayar una mayor presencia de personajes femeninos en aquellos roles de carácter dependiente (como por ejemplo el de esposa o madre); una mayoría que se hace especialmente patente si tiene en cuenta que los personajes femeninos 
analizados se corresponden con la totalidad del universo de análisis, mientras que los masculinos solamente suponen una parte de éste.

\subsection{Localización espacial}

Si se atiende a la localización de los personajes según el género, estrechamente vinculada a la tipología de rol asumido, se aprecian diferencias en el emplazamiento de personajes femeninos y masculinos. Unas diferencias que se corresponden -de algún modo- con una concepción tradicional de la distribución espacial, que reserva a las mujeres los espacios interiores-domésticos, dejando para los varones los exteriores.

La diferencia sustancial que presenta el medio radiofónico, con respecto a los restantes media, es que sus anuncios no necesitan de un espacio concreto para el desarrollo de la interacción publicitaria. Un espacio indefinido que resulta menos común en el ámbito de la publicidad audiovisual o gráfica.

El análisis de las localizaciones en función del género ofrece resultados similares en lo que respecta a aquellas ubicaciones más frecuentes de los personajes de la muestra, es decir, en el espacio "no relevante" y en la situación en un entorno laboral. No obstante, se pueden señalar diferencias de interés en la localización de personajes femeninos y masculinos en los restantes espacios, utilizados como categoría de análisis en la muestra de estudio. 
Gráfico 4. Localización de los personajes en función del género.

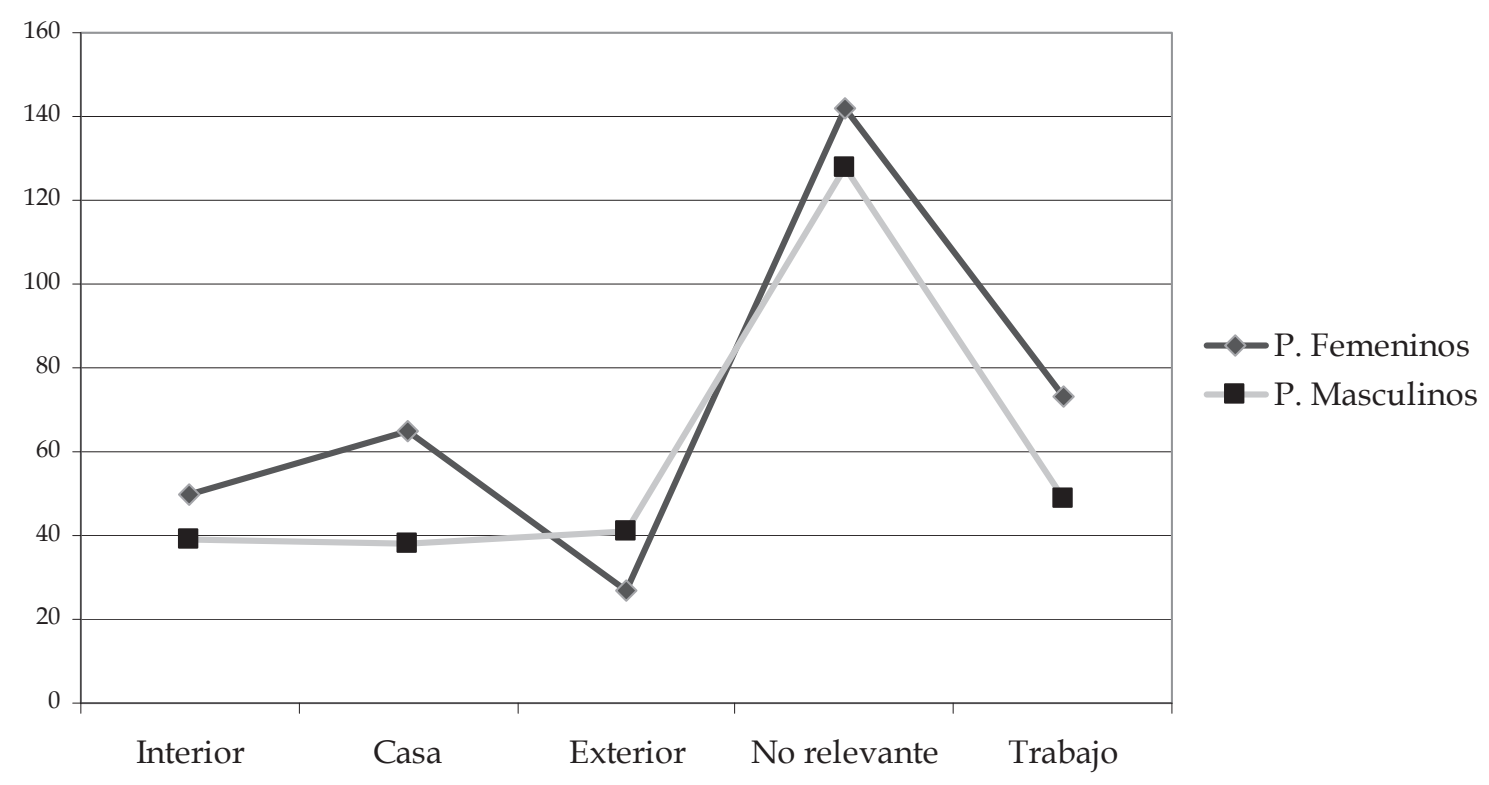

Fuente. Elaboración propia.

En estas localizaciones, los personajes femeninos se presentan mayoritariamente situados en espacios domésticos (18\%) e interiores (13\%), mientras que los protagonistas masculinos aparecen ubicados en exteriores $(14 \%) \mathrm{y}$, con valores muy similares, en espacios domésticos e interiores (13\%). Una localización equilibrada de los personajes masculinos de la muestra en espacios exteriores, interiores y domésticos, fruto de la particular selección de la muestra de estudio.

\subsection{Rasgos lingüísticos}

En busca de determinar aquellas particularidades lingüísticas que caracterizasen las representaciones de género de la muestra, al igual que los atributos visuales en la televisión o la publicidad gráfica, se establecieron dos clasificadores diferentes: registro y acento. 
Gráfico 5. Registro lingüístico utilizado por los personajes en función del género.

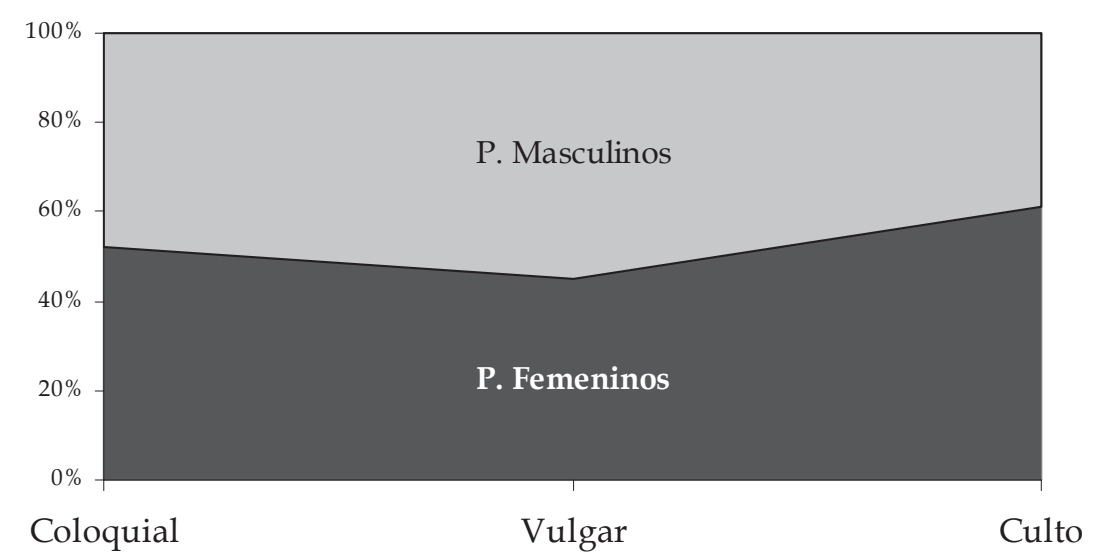

Fuente. Elaboración propia.

Clasificadores que, pese a conseguir resultados interesantes, no fueron determinantes para la caracterización de estereotipos femeninos y/o masculinos.

\subsection{Relaciones establecidas en el anuncio}

En cuanto al tipo de relación establecida entre los dos personajes principales de la muestra objeto de estudio, se pueden distinguir diferentes tipos de interacción según los roles asumidos dentro del relato publicitario. Unas interacciones en las que destacan las relaciones de complementariedad y contrapunto.

De hecho, aquellas interacciones que se establecen entre los roles considerados complementarios: padre/madre-hijo, esposo-esposa, novio-novia, maestro-alumno, etc. supusieron cerca de la mitad de la muestra analizada (el $41 \%$ de las piezas de la muestra). Mientras que las consideradas como contrapunto, cuya relación está marcada por la interacción de un timbre vocálico masculino y otro femenino, se correspondieron con el $10 \%$ de la muestra. 
Gráfico 6. Tipología de relaciones establecidas entre los protagonistas.

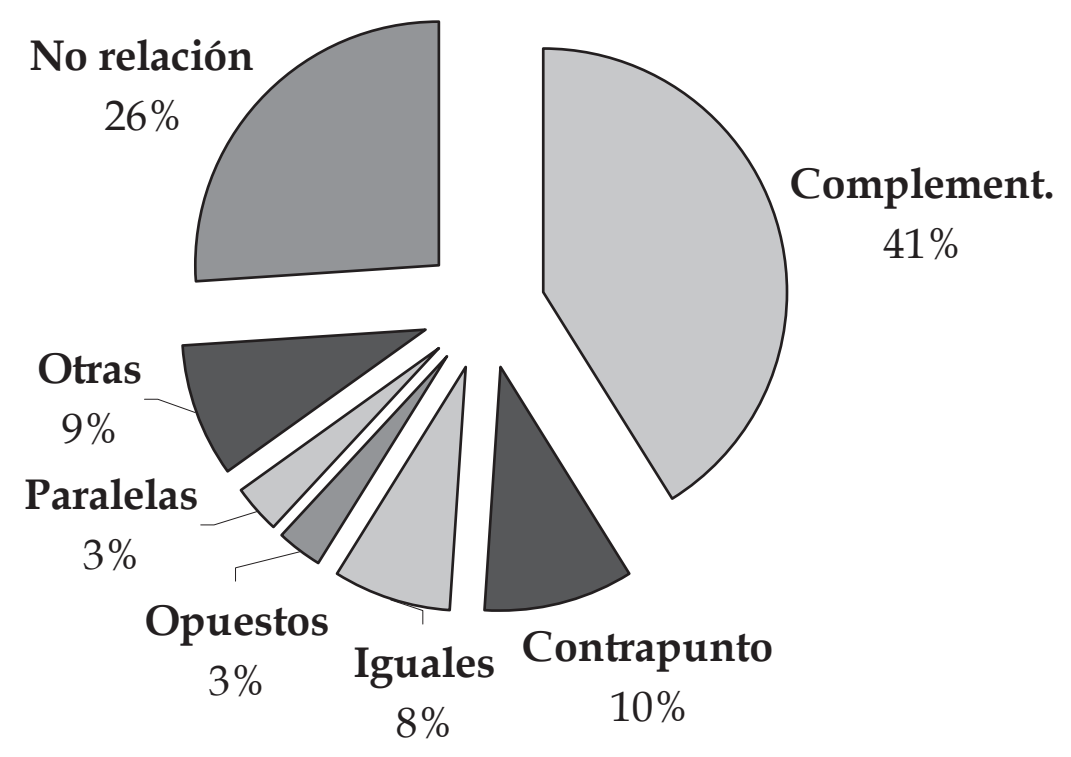

Fuente. Elaboración propia.

Otras relaciones establecidas dentro de los mensajes publicitarios objeto de estudio son las de iguales, o interacciones entre pares del mismo género como vecinas/os o compañeras/os ( $8 \%$ de la muestra, de las cuales un $6 \%$ se corresponde con relaciones femeninas entre pares); las paralelas, o relaciones establecidas entre iguales de distinto género ( $3 \%$ de las piezas a analizadas); y las contrarias o aquellas establecidas entre personajes contrapuestos como por ejemplo los arquetipos del bueno y el malo, y su concreción en las representaciones de ladrón-policía, atracador-héroe, etc. (con otro 3\%).

El predominio de las relaciones de complementariedad dentro de los anuncios objeto de estudio remiten a una situación de corte tradicional, tanto desde el punto de vista social como del publicitario: madre/padre, madre/hijo, esposo/esposa...

En definitiva, el análisis desarrollado ha permitido señalar la existencia de diferencias en la representación de los personajes en función del género, al tiempo que corroboró la 
existencia -también en la publicidad radiofónica española- de estereotipos femeninos y masculinos de carácter sexista.

\section{COMPARACIÓN CON ESTUDIOS PREVIOS}

Tal y como se ha podido constatar con el análisis de la muestra de estudio, la representación de personajes femeninos y masculinos responde a diferentes trayectorias, especialmente de atender a su presencia y orden en el relato, a los roles asumidos dentro del anuncio o a su localización espacial.

Esta diferencia en la construcción e personajes femeninos y masculinos en la publicidad ya había sido señalada por McArthur y Resko quienes en su trabajo, considerado de referencia en los estudios en torno a género y publicidad, analizaron pormenorizadamente el tipo de representaciones de género existentes en la publicidad televisiva del momento.

En su investigación, dichas autoras concluyeron que los varones aparecían sobrerrepresentados en los anuncios de televisión, en comparación con las mujeres; sobrerrepresentación a la que se suman otras diferencias en lo que respecta a la credibilidad (los hombres aparecen más frecuentemente retratados como autoridades), rol (las mujeres son presentadas por el tipo de relaciones que mantienen), localización (los personajes femeninos se sitúan con más frecuencia en espacios domésticos), argumentos aportados (los personajes varones suelen hacer uso de argumentos más científicos que las mujeres), recompensa (los protagonistas masculinos suelen estar asociados a recompensas que implican ascenso social y laboral mientras que los personajes femeninos pretenden la aprobación de los suyos) y el tipo de producto.

En el ámbito concreto de las investigaciones en torno a la estereotipia de género en el medio sonoro, el estudio pionero de Furnham y Schofield apenas encontró distinciones significativas respecto a las señaladas para la publicidad televisiva. Circunstancia que 
llevó a subrayar, como característica diferencial, la existencia -en la publicidad radiofónica- de una menor variedad de representaciones de género.

El análisis de las conclusiones aportadas por ambos estudios de referencia, "The portrayal of men and woman in American televisión commercials" y "Sex role stereotyping in British radio advertisements" y su comparación con los resultados obtenidos para la publicidad radiofónica española, delata una escasa evolución de las representaciones publicitarias de género en las últimas décadas.

Por esta razón, en busca de situar los resultados de este trabajo en un ámbito de estudio más amplio, se consideró la comparación entre los datos obtenidos del análisis de la publicidad presentada al Festival Publicitario de San Sebastián y aquellos aportados por los trabajos más recientes en torno a las representaciones de género en la publicidad radiofónica (Furham y Thonson, 1999; o Neto y Santos, 2004). Comparación para la que fue preciso tener en cuenta que, mientras los trabajos de Furham y Thomson o Neto y Santos analizaron el conjunto de la publicidad seleccionada, el presente estudio se refirió exclusivamente a aquellas piezas inscritas en el Festival de San Sebastián con presencia femenina.

Esta diferencia en la concepción de la muestra de estudio tuvo repercusión en algunas de las conclusiones obtenidas y, por ende, en su comparación. En este sentido, siempre que fuese posible, se procuró establecer una relación con el universo de análisis de la investigación.

A la hora de establecer una comparación entre los tres estudios (los dos trabajos precedentes en el ámbito europeo y éste) fue preciso simplificar algunas categorías de análisis (credibilidad y roles) para aproximarse a aquellas establecidas en los trabajos precedentes, en particular al de Furham y Thomson (1999) dada su menor variedad categorial. 
Tabla 2. Principales variables de los tres estudios analizados.

\begin{tabular}{|l|c||c||c|}
\hline \multicolumn{4}{|c|}{ COMPARACIÓN DE LAS PRINCIPALES VARIABLES } \\
\hline & REINO UNIDO & PORTUGAL & ESPAÑA \\
\hline MUESTRA DE ESTUDIO & $\mathrm{N}=254$ & $\mathrm{~N}=233$ & $\mathrm{~N}=652$ \\
\hline PESONAJES FEMENINOS DE LA MUES & $21 \%$ & $21 \%$ & $55 \%$ \\
\hline PERSONAJE CENTRAL & P. MASCULINOS $(79 \%)$ & P. MASCULINOS $(79 \%)$ & P. FEMENINOS $(55 \%)$ \\
\hline CREDIBILIDAD: AUTORIDAD & P. MASCULINOS $(84 \%)$ & P. MASCULINOS( $80 \%)$ & NO RELEVANTE \\
\hline CREDIBILIDAD: USUARIO & NO RELEVANTE & P. FEMENINOS( $29 \%)$ & P. MASCULINOS( $23 \%)$ \\
\hline ROL: DEPENDIENTE & P. FEMENINOS (8\%) & P. FEMENINOS $(29 \%)$ & P. FEMENINOS $(32 \%)$ \\
\hline ROL: NARRADOR/CELEBRIDAD & P. MASCULINOS (75\%) & P. MASCULINOS60\%) & P. MASCULINOS $(10 \%)$ \\
\hline LOCALIZACIÓN: HOGAR & P. FEMENINOS (4\%) & MULLERES $(18 \%)$ & P. FEMENINOS(18\%) \\
\hline
\end{tabular}

Fuente. Elaboración propia.

Una vez señaladas dichas particularidades en el tratamiento y comparación de los tres estudios, se hace preciso profundizar en sus similitudes y diferencias en lo que respecta a la presencia de estereotipos de género en la publicidad radiofónica de cada uno de los tres países.

Como se puede observar en la tabla precedente (tabla 2) existen diversos puntos de confluencia en dichos estudios, entre los que destaca la superioridad de los personajes masculinos en la interacción publicitaria. Solo en el presente trabajo, dada la particular selección de la muestra, existe una mayoría femenina; proporción que va a reflejarse en los personajes centrales de cada anuncio.

Otra de las coincidencias existentes en los tres estudios es el tipo de roles desempeñados por personajes masculinos y femeninos en la publicidad. Los resultados aportados por los análisis de la publicidad radiofónica británica, portuguesa y española señalan una mayor presencia de protagonistas femeninas en roles dependientes mientras que los varones aparecen mayoritariamente asociados a narrador/celebridad. 
En cuanto a la localización espacial de los personajes en el relato publicitario, los tres estudios coinciden en situar a las mujeres, más frecuentemente que a los hombres en el espacio doméstico. Circunstancia que remite a una concepción tradicional del espacio en función del género del personaje.

El tratamiento que la publicidad radiofónica española confiere a las representaciones masculinas y femeninas en sus mensajes, presenta características comunes a las señaladas por Furham y Thomson (1999) y Neto y Pinto (2004) para la publicidad británica y portuguesa. Unas características que, inclusive, cuentan con elementos coincidentes respecto a los resultados obtenidos por Furham y Schofield en 1986. La confluencia de elementos en dichas investigaciones, pese a su distancia temporal y geográfica, pone de relevancia la estabilidad de las representaciones de género en la publicidad sonora.

\section{CONCLUSIONES}

El estudio llevado a cabo ha permitido determinar la existencia de diferencias en el tratamiento que la publicidad radiofónica da a las representaciones de género en sus mensajes. Este desigual tratamiento se hace patente en variables como la credibilidad del personaje (autoridad, prescriptor o usuario), el rol desempeñado, el espacio donde se desarrolla la interacción o el tipo de relaciones establecidas en ésta.

A pesar de que, la propia selección de aquellos anuncios con personajes femeninos como muestra de análisis limitó la presencia de diferencias determinantes en la construcción de los personajes en función del género, el análisis desarrollado ha permitido subrayar el carácter convencional de dichas representaciones. Una circunstancia que adquiere mayor entidad si se toma como referencia el orden de los personajes en el relato.

Los personajes femeninos continúan siendo mayoría en aquellos papeles que tradicionalmente le asignó la publicidad, como el de ama de casa, madre, esposa; además 
de situarse con mayor frecuencia que sus homólogos masculinos en espacios interioresdomésticos.

Estas diferencias en la construcción de los personajes femeninos y masculinos en los mensajes publicitarios radiofónicos confirman la existencia de una serie de estereotipos género de índole similar a los vehiculados por la televisión, cuyo exceso de visualización la convierten en el medio con mayor número de denuncias por publicidad sexista.

En lo que respecta a la comparación de los resultados obtenidos en el ámbito de la publicidad radiofónica española con los señalados por Furham y Thomson (1999) y Neto y Santos para la publicidad británica y lusa, respectivamente, se han podido determinar coincidencias relevantes en el tratamiento de las representaciones de género. Coincidencias entre las que destaca una infrarrepresentación de los personajes femeninos respecto a los masculinos, que va a reflejarse en los personajes principales dentro de la interacción publicitaria.

Otros elementos de confluencia en los tres estudios son la mayor presencia de personajes femeninos en roles de carácter dependiente, mientras que los personajes masculinos son mayoría en papeles como el de narrador o celebridad. Una distribución de roles en función del género que va a traducirse en una mayor presencia de los personajes femeninos en aquellos espacios asociados al ámbito doméstico; presencia que ha sido refrendada por los tres estudios.

El análisis del tratamiento publicitario que la radio da a las representaciones de género en el ámbito español, así como su comparación con sendos estudios desarrollados en el contexto europeo, han permitido subrayar la existencia de relevantes coincidencias respecto al estudio de McArthur y Resko (1975). Unas coincidencias que, de tener en cuenta la intensa transformación económica y social sufrida en las últimas tres décadas, ponen de relevancia la escasa permeabilidad al cambio social de las representaciones 
publicitarias de género, particularmente en lo que se refiere a la construcción de los personajes femeninos en el relato.

\section{BIBLIOGRAFÍA}

- BERGANZA, M. R y DEL HOYO, M. “La mujer y el hombre en la publicidad televisiva: imágenes y estereotipos". En Revista: Zer, nº 21. 2006. Pág. 161-175.

- BIGNÉ, J. E y CRUZ, S.: “Actitudes hacia los roles de género en la publicidad. Efectos sobre la imagen de empresa y la intención de compra". En Revista: Cuadernos de Economía y Dirección de la Empresa, nº 6. 2000. Pág. 165-186.

- COURTNEY, A. y LOCKERETZ, S.: “A woman's place: an analysis of the roles portrayed by women in magazine advertisements". En Revista: Journal of Marketing Research, no 8. 1971. Pág. 92-95.

- COURTNEY, A. y WHIPPLE, T.: “Women in TV Commercials". En Revista: Journal of Communication, $\mathrm{n}^{\mathrm{O}} 24$. 1974. Pág. 110-118.

- DE PABLOS, J.M. (dir.): "Los nuevos modelos de mujer y de hombre de la publicidad televisiva actual". Equipo Latina de Comunicación Social. 2005. En http:/ / www.eccc.ucr.ac.cr/pdfs/consejocataluna.pdf (12/10/2010).

- DURKIN, K.: “Television and sex-role acquisition. I Content". En Revista: British Journal of Social Psychology, vol. 24, nº 3. 1985. Pág. 101-113.

- DURKIN, K.: "Television and sex-role acquisition. II Effects". En Revista: British Journal of Social Psychology, vol. 24, no 3. 1985. Pág. 191-210.

- DURKIN, K.: "Television and sex-role acquisition. III Counter-stereotyping". En Revista: Journal of Social Psychology, vol. 24, nº 3. 1985. Pág. 211-222.

- FAJUlA, A., FERNÁNDEZ SOUTO, A.B y BARBEITO, M.L. : "Publicidad y género. Los estereotipos de la mujer en la publicidad radiofónica del 'prime time' generalista". En Actes de Congènere: la representació de gènere a la publicitat del segle XXI, Girona, 2010. Universitat de Girona. 
- FURHAM, A. y SCHOFIELD, S.: "Sex role stereotyping in British radio advertisements". En Revista: British Journal of Social Psychology, n² 25. 1986. Pág. 165-171.

- FURHAM, A. y THOMSON, L.: “Gender role stereotyping in advertisements on two British radio stations". En Revista: Sex Roles, vol. 40, nº 1-2. 1999. Pág. 153-165.

- GIL, E.M.: "Los estereotipos de la mujer en la publicidad radiofónica". En DURÁN, M.A.; VIEDMA, M. (coords.): Mujeres, simbolismo y vida. Málaga, 2007. Servicio de Publicaciones de la Universidad de Málaga, Pág. 79-96.

- GILLY, M.C.: "Sex roles in advertising: a comparison of televisión advertisements in Australia, Mexico, and the United States". En Revista: Journal of Marketing, $\mathrm{n}^{\mathrm{o}} 52$. 1988. Pág. 75-85.

- GOFFMAN, E.: “Gender advertisements". Londres, 1979. Macmillan.

- HURTZ, W. y DURKIN, K.: "Gender role stereotyping in Australian radio commercials". En Revista: Sex Roles, vol. 36, nº 1-2. 1999. Pág. 103-114.

- INSTITUTO DE LA MUJER: “Observatorio de la imagen de las mujeres. Informe de 2008" Madrid, $2009 . \quad$ En http://www.inmujer.migualdad.es/mujer/medios/publicidad/informes/2008/I nforme\%202008.pdf (09/05/2010).

- MCARTHUR, L. y RESKO, B.: “The portrayal of men and women in America n televisión commercials". En Revista: The Journal of Social Psychology, no 97. 1975. Pág. 209220.

- NETO, F. y SANTOS, A.: “Gender role stereotyping in radio advertisements: a portuguese and cross-national analysis". En Revista: Journal of Radio Studies, vol. 11, $\mathrm{n}^{\mathrm{o}} 1$, . 2004. Pág. 131-145.

- PEÑA MARÍN, C. y FABRETTI, C.: "La mujer en la publicidad". Madrid, 1990. Instituto de la Mujer, Ministerio de Trabajo y Asuntos Sociales.

- ROYO, M., ALDÁS, J., KÜSTER, I. y VILA, N.: “Roles de género y sexismo en la publicidad de las revistas españolas: un análisis de las tres últimas décadas del siglo XX". En Revista: Comunicación y Sociedad, vol. XVIII, nº 1. 2005. Pág. 113152. 
- SÁNCHEZ ARANDA, J.J., GARCÍA ORTEGA, C., GRANDÍO, M. y BERGANZA, M.R.: El espejo mágico. La nueva imagen de la mujer en la publicidad actual. Pamplona, 2002. Instituto Navarro de la Mujer. 